\title{
Reflections on West Virginia's Early COVID-19
}

\section{Experience}

\author{
Stephen M. Petrany, MD'1, Deb Koester, PhD, DNP'1, \\ Robert Walker, MD'
}

ABSTRACT

The nation is in the throes of a pandemic. COVID-19 has advanced across the United States, impacting all of our states in different ways and at different rates. Predictive models have ranked West Virginia as the most fragile state, based on the percentage of elderly and the prevalence of serious chronic diseases. Early predictions forecasted more than 2,000 deaths in the initial wave of the illness. These dire predictions have, so far, been not only inaccurate but grossly so.

\section{KEYWORDS}

Coronavirus, Rural, COVID-19
Author affiliations are listed at the end of this article.

Correspondence to: Stephen M. Petrany, MD Marshall University Joan C. Edwards School of Medicine petrany@marshall.edu
The nation is in the throes of a pandemic. COVID-19 has advanced across the United States, impacting all of our states in different ways and at different rates. Predictive models have ranked West Virginia as the most fragile state, based on the percentage of elderly and the prevalence of serious chronic diseases. Early predictions forecasted more than 2,000 deaths in the initial wave of the illness. These dire predictions have, so far, been not only inaccurate but grossly so. As of this writing, West Virginia, along with Maine, are the only two states east of the Mississippi with fewer than 1000 cases and fewer than 40 deaths statewide. Early on, state leadership acted decisively and health care systems rapidly transformed to meet the impending challenge. We believe these laudable efforts represent only part of the explanation. Obviously, this story is still unfolding and is far from over, but what insights can these unexpectedly favorable outcomes offer? What attributes of our communities and our people have helped define the West Virginia experience?

Disasters are not new to Appalachia's rural communities. Floods, destruction from high winds, and waste impoundment failure have occurred with tragic regularity. In West Virginia, the only state located entirely in Appalachia, nearly half of us live in rural, geographically isolated areas. We have no cities with a population of 50,000 or more. We have no international, or even large, airports. As a result, rural Appalachians have some degree of "social isolation" built into their normal, everyday lives. Rural West Virginians embrace outdoor activities that usually involve few participants: farming, gardening, hunting, fishing, four-wheeling. Rural Appalachian communities have learned to make do with existing and often meager resources and economic deprivation has been a common experience. Although help is welcomed from the outside, rural communities have come to understand that they cannot always wait for, or rely on, external assistance.

Rural Appalachian communities form tightly woven groups around churches, schools, and neighborhoods. There is an immediate communitywide concern for the old and the disabled. Elders tend to check on each other by whatever means they find available, whether it be a phone, internet, or in person. Neighborhoods, churches, school groups, and others such as garden clubs, volunteer fire departments, EMT services, Future Farmers of America, and service clubs have closely shared 
communications. These organizations represent groups who know and trust one another and are active within their communities. The faith community is strong in rural West Virginia and has a long tradition of maintaining regular contact and support. Religious organizations in rural communities often have a strong organizational base and a clear mission of outreach and service that is supported by established resources and facilities. They have been creative in maintaining fellowship in new ways during the pandemic (virtually when possible), while mostly encouraging compliance with the needed restrictions.

Local health services are critical to rural communities at times like these. West Virginia's community health centers, individual rural primary care providers, and local health departments are usually staffed and administrated by people from that community, giving them a unique understanding of the community and its priorities. These local healthcare insiders can marshal critical support and credibility when needed. Rural Appalachians have great respect for physicians and other health providers. Although Appalachians are known for their fierce independence they will often listen to their personal healthcare providers about such issues as social isolation and the importance of changing precious traditions like funerals and in-person church services.

Despite these fundamental strengths of our rural communities, West Virginia has many formidable obstacles to overcome as this epidemic, and its aftermath, unfolds. Many of our small rural hospitals were struggling with sustainability long before the pandemic. The wonderful dearth thus far of patients with the coronavirus, along with public constraints designed to minimize viral spread, have left our medical centers and offices strikingly underused and seriously financially challenged. While many health practices and health systems have turned to telehealth methods to fill gaps in care, limitations in cell phone service and bandwidth make it difficult to provide virtual services to our most isolated citizens. The opioid and substance use epidemic that preceded the present COVID-19 crisis remains a serious problem for the state. Our determined labors to manage the opioid crisis have been made even more difficult by the arrival of the coronavirus. West
Virginia leads the nation in grandparents and greatgrandparents raising their grandchildren, presenting additional risks to both elders and the very young they care for during the pandemic. Residents of long-term care facilities appear to be at especially high risk and makeup at least $25 \%$ of our current COVID-19 cases. Compulsory school and business closures threaten the already delicate economic fabrics of many of our small towns.

The mission of the Joan C. Edwards School of Medicine at Marshall University is "to meet the unique healthcare needs of West Virginia and Central Appalachia." We are charged by this very mission to constantly reconsider the distinctive needs and challenges faced by the rural and smalltown communities that we serve. Especially during this pandemic, we can see that our communities have demonstrated their knowledge, will, and responsiveness to the special needs of their people. If we in health care are to be at all helpful, we must turn to our rural and small-town communities to ask the right questions while offering to collaborate on the right solutions as the COVID-19 crisis moves forward. This pandemic has brought very real suffering to our region and no doubt there will be more suffering ahead. Hopefully, the natural acceptance of rural West Virginians of "spreading out" and staying home, of non-dependence on public transportation, of caring for one another, and of "making do with less," will continue to prove the models wrong. In the meantime, those of us providing health care to our fellow West Virginians must adapt as our patients do, recognizing and factoring in those strengths and weaknesses that make us who we are.

\section{AUTHOR AFFILIATIONS}

1. Marshall University Joan C. Edwards School of Medicine, Huntington, West Virginia 